\title{
Perspective
}

PERSPECTIVE Actualité en histoire de l'art

$1 \mid 2020$

Japon

\section{Quelques réflexions sur la culture japonaise et l'érotisme}

\section{Natsuki Ikezawa}

Traducteur : Corinne Quentin

\section{OpenEdition \\ Journals}

Édition électronique

URL : http://journals.openedition.org/perspective/19607

DOI : 10.4000/perspective. 19607

ISSN : 2269-7721

\section{Éditeur}

Institut national d'histoire de l'art

\section{Édition imprimée}

Date de publication : 5 juin 2020

Pagination : 347-350

ISBN : 978-2-917902-89-9

ISSN : $1777-7852$

\section{Référence électronique}

Natsuki Ikezawa, «Quelques réflexions sur la culture japonaise et l'érotisme », Perspective [En ligne], 1 | 2020, mis en ligne le 30 décembre 2020, consulté le 25 janvier 2021. URL : http://

journals.openedition.org/perspective/19607; DOI : https://doi.org/10.4000/perspective.19607 


\title{
Quelques réflexions sur la culture japonaise et l'érotisme
}

\author{
Ikezawa Natsuki
}

Quand je réfléchis à une question historique, j'ai une certaine tendance à m'intéresser d'abord aux conditions préalables que sont les données naturelles de la géographie.

Oui, la géographie est très importante. Par exemple, sans ce territoire hexagonal délimité par les Alpes, les Pyrénées, la Méditerranée, le Golfe de Gascogne et le bras de mer qu'est la Manche, le pays appelé « France » ne se serait pas constitué. Pour le Japon, on peut dire que la configuration géographique a orienté de façon déterminante les caractéristiques du pays.

Le Japon est un ensemble d'îles.

Et cet archipel se trouve à parfaite distance du continent. Parfaite : c'est-à-dire que la mer qui les sépare était franchissable même avec les moyens de transport antiques mais qu'elle était tout de même assez large pour faire obstacle à d'éventuelles tentatives d'invasion. Sur le continent, s'est développée la riche civilisation chinoise, dont les représentants pouvaient facilement passer vers l'Archipel afin d'y apporter les arts et les sciences; dans l'autre sens, il était tout aussi aisé d'aller du Japon vers la Chine. En revanche envoyer une force militaire suffisante pour occuper ces multiples îles, c'était une autre affaire, si bien que, du IV siècle, lorsqu'il s'est constitué en tant que pays, jusqu'en 1945, le Japon n'a jamais connu la domination d'un peuple étranger. Peu de pays dans le monde ont joui d'une telle stabilité territoriale. La mentalité du peuple japonais en a été grandement influencée.

Or, sur les îles, les phénomènes peuvent avoir tendance à prendre des orientations extrêmes. Prenons l'exemple de l'églantier : dans les îles du Pacifique, il se trouvait à l'abri des herbivores et a donc fait disparaître ses épines, afin de ne pas dépenser d'éléments nutritifs à des fonctions inutiles (puis le Capitaine Cook arriva avec des chèvres qu'il laissa sur place pour les marins qui viendraient après lui, et le résultat fut le quasi anéantissement de ces sortes de roses sans épines).

Dans la culture japonaise, l'érotisme a pris une importance toute particulière.

Un mythe raconte que le monde serait né de la relation sexuelle entre deux divinités, l'une féminine, Izanaki, et l'autre masculine, Izanami. Leurs noms dérivent du verbe izanau, "inviter". Le monde aurait donc commencé par leur invitation réciproque à une relation sexuelle. 
Là encore, le climat de l'archipel intervient : un fort ensoleillement et des pluies importantes, dans une zone soumise à la mousson, font que le riz - qui affectionne les marécages tropicaux - et toutes sortes d'autres plantes s'y développent avec luxuriance. C'est ce qui explique sans doute pourquoi le verbe naru (" devenir, se faire ") est si fondateur dans la vision du monde japonaise : le plaqueminier porte des fruits qui deviennent / se font kakis, de même qu'un enfant devient / se fait adulte. Naru : l'action interne de la force que renferme une chose donne naissance à une autre chose. Sans l'intervention d'aucun dieu tout-puissant, chaque être vivant de l'univers, plante ou animal, se développe à son gré.

Les Japonais ont été fascinés par ce principe naturel et en ont tiré une sorte d'animisme que reflète leur système mythologique. Ils ont aussi mené leurs relations sexuelles selon ce principe, les associant magiquement à leurs prières pour l'abondance des récoltes. Certes, ces associations ont cours dans d'autres régions du monde, Lévi-Strauss l'a montré dans La Pensée sauvage. Mais ce qui est frappant chez les Japonais, c'est qu'ils ont fait de ce principe sexuel la force motrice de leur littérature, au moins jusqu'au XIX siècle. L'expression de la puissance érotique, dont l'origine se trouve dans le récit de la rencontre d'Izanaki et Izanami, est devenue plus subtile, moins manifeste, mais elle a continué à travailler la littérature dans son fond. Je dirais même que ce lent processus de raffinement est ce qui fait l'histoire de la littérature japonaise.

Il y a bien longtemps, juste après les temps mythologiques, une jeune femme anonyme fait le récit suivant :

Celui qui m’a entraînée dans le bois, je n’en connais ni le visage ni le nom.

Viol ou relation sexuelle consentie ? En tout cas, si cet acte a donné lieu à un poème qui a été ensuite transmis aux générations suivantes, c'est parce qu'il était lié, d'une certaine façon, à une prière pour la fertilité.

Plusieurs siècles plus tard, une jeune poétesse, Izumi Shikibu, écrit :

Inconsciente du désordre de ma chevelure noire / en position de levrette l'homme qui a relevé mes cheveux / à présent me manque

Après une relation sexuelle intense, les partenaires ont perdu conscience (la petite mort). L'homme reprend le premier ses esprits, soulève la chevelure de la femme et regarde son visage. Longtemps après, quand, seule, la femme se rappelle ce qui s'est passé, elle est assaillie par l'émotion. Exprimer tout cela en trente et une syllabes seulement, voilà à quoi se sont attachés les poètes japonais. Cela dit, la prose n'est pas en reste : dans Le Dit du Genji, premier roman fleuve de la littérature mondiale, les personnages, comme chez Proust (mais mille ans plus tôt), prennent conscience du travail du temps à travers la sexualité, thème central au même titre que la magie et la politique.

Avec le temps, l'érotisme s'est épuré et est devenu discret au point de n'être plus évoqué que de façon allusive. Basho, dans son recueil de poèmes de voyage Okuno hosomichi ${ }^{1}$, écrit :

Dans la maison la fille de joie dort aussi / un magnolia et la lune

Pas le moindre échange entre le poète vagabond et la prostituée en voyage. Ils se sont simplement retrouvés par hasard dans la même auberge. Le lendemain, ils se sépareront. La prostituée était en route vers le sanctuaire d'Ise. Imaginez un poète et une prostituée qui se croisent sur le chemin de Compostelle.

Sur ce plan de l'érotisme et de la sexualité, les Japonais se démarquent de la Chine : l'abondante littérature japonaise consacrée à ces thèmes contraste avec la rareté de la poésie amoureuse dans la Chine confucéenne, où le désir amoureux entre homme 
et femme n'était pas un sujet convenable. C'est pourquoi Li Bai ou $\mathrm{Du} \mathrm{Fu}^{2}$, par exemple, n'ont pas écrit de poèmes sur l'amour ni, à plus forte raison, sur l'amour libre ; il a fallu attendre beaucoup plus tard pour qu'apparaissent des romans évoquant cette dimension, comme Jin Ping Mei ${ }^{3}$ ou Hong Lou Meng ${ }^{4}$.

Qu'en est-il dans le domaine des beaux-arts?

La relation sexuelle étant un acte intime, il n'est pas question de l'exposer en public. Les peintres de l'école Rinpa, au XVII siècle, n'ont pas peint de scènes érotiques (dites shunga) sur des fusuma, ces cloisons intérieures des habitations, ni sur des paravents. En revanche, les estampes érotiques se sont largement répandues à l'époque d'Edo. Le papier était devenu bon marché, la technique de la gravure sur bois avait progressé. Le bas prix de ces estampes venait de la possibilité de les reproduire à plusieurs centaines d'exemplaires. Les acheteurs étaient nombreux, les artistes de génie aussi, et un vaste marché s'est développé. Le peuple d'Edo, bourgeois citadins ou samouraïs de classes inférieures, achetait ces peintures reproductibles qu'étaient les estampes du monde flottant. Elles faisaient partie de ces plaisirs de la vie quotidienne que recherchent les membres d'une société relativement stable, lorsqu'une certaine aisance s'installe, au même titre que les spectacles, les fêtes diverses, les voyages d'agrément, la pratique de l'art du thé ou de la poésie. Et les Japonais ont alors librement appliqué leur culture picturale à la représentation de scènes érotiques.

Il faut souligner que ces estampes érotiques shunga représentent le bonheur. Dans ces images, la jouissance n'est pas liée à la violence, mais s'accomplit sur fond de scènes de la vie quotidienne et de coutumes qui rythment le calendrier de l'année. La sexualité va avec la joie de vivre. C'est dire que le terme de pornographie ne convient pas pour qualifier ces scènes. Étymologiquement, ce mot renvoie à la prostitution alors que les femmes des estampes shunga sont le plus souvent des non professionnelles.

Il ne s'agit pas non plus d'images réalistes. La représentation est subjective. Si les organes sexuels apparaissent disproportionnés, c'est parce que les artistes - Utamaro ou Kiyonaga, par exemple - ont focalisé leur attention sur eux. Le monde s'appréhende par le biais de la conscience que l'être humain en a. En se fondant sur cette vision subjective, l'important, pour le peintre d'estampes, c'est de surprendre le spectateur, d'attirer son admiration, de le charmer. Sans se sentir prisonnier de la réalité qui se trouve devant ses yeux ni des lois de la perspective, il rivalise d'audace dans la recherche d'originalité du dessin. Comme dans la poésie à forme fixe, les contraintes stimulent la création et l'incitent à voler de ses propres ailes dans les mondes qu'il crée : il s'accorde toutes les libertés pour faire le portrait de comédiens ou de belles personnes, et c'est aussi la raison pour laquelle il exagère les organes sexuels dans les estampes érotiques.

Dans la seconde moitié du XIX siècle, sous l'influence des principes d'austérité de l'ère victorienne, cette représentation de l'univers érotique s'est interrompue au Japon. Une version non censurée de L'Amant de Lady Chatterley, par exemple, a été publiée en Angleterre en 1960, mais n'a été autorisée au Japon qu'en 1973, par décision de la Cour Suprême. La libération de l'expression sexuelle ces trente dernières années est aussi une importation anglo-saxonne, mais c'est une autre histoire. Aujourd'hui, nous n'associons plus les relations sexuelles à des prières pour d'abondantes récoltes. Nous avons sans doute perdu notre vision animiste du monde. Du point de vue de l'écologie, la retrouver ne me semblerait pas manquer de sens. 


\section{NOTES}

1. La Sente étroite du bout du monde. Il existe diverses traductions, $\mathrm{NdT}$.

2. Deux célèbres poètes de la dynastie Tang, NdT.

3. La Fleur en fiole d'or ou Le lotus d'or, NdT.

4. Le Rêve dans le pavillon rouge, NdT. 